\title{
A Model for Determining When an Analysis Contains Sufficient Detail to Provide Adequate NEPA Coverage for a Proposed Action
}

Prepared for the U.S. Department of Energy Office of Environmental Restoration and Waste Management

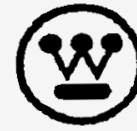

Hanford Operations and Engineering Contractor for the U.S. Department of Energy under Contract DE-AC06-87RL10930

Copyright License By acceptance of this article, the publisher and/or recipient acknowledges the U.S. Govemment's right to retain a nonexclusive, royalty-free license in and to any copyright covering this paper.

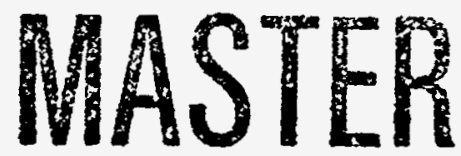

Approved for Public Release

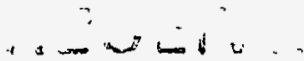

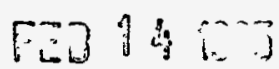




\section{DISCLAIMER}

\section{Portions of this document may be illegible in electronic image products. Images are produced from the best available original document.}




\section{A Model for Determining When an Analysis Contains Sufficient Detail to Provide Adequate NEPA Coverage for a Proposed Action}

C. H. Eccleston

Date Published

November 1994

To Be Published in

Scientific Journal

Prepared for the U.S. Department of Energy Office of Environmental Restoration and Waste Management

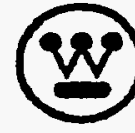

Hanford Operations and Engineering Contractor for the U.S. Department of Energy under Contract DE-AC06-87RL10930

Copyright License $8 y$ acceptance of this article, the publisher and/or recipient acknowledges the U.S. Govemment's right to retain a nonexciusive, royalty-free license in and to any copyright covering this paper. 
LEGAL DISCLAIMER

This report was prepared as an account of work sponsored by an agency of the United States Government. Neither the United States Government nor any agency thereof, nor any of their employees, nor any of their contractors, subcontractors or their employees, makes any warranty, express or implied, or assumes any legal liability or responsibility for the accuracy, completeness, or any third party's use or the results of such use of any information, apparatus, product, or process disclosed, or represents that its use would not infringe privately owned rights. Reference herein to any specific commercial product, process, or senice by trade name, trademark, manufacturer, or otherwise, does not necessarily constitute or imply its endorsement, recommendation, or favoring by the United States Government or any agency thereof or its contractors or subcontractors. The views and opinions of authors expressed herein do not necessarily state or reflect those of the United States Government or any agency thereof.

This report has been reproduced from the best available copy.

Frinted in the United States of Americe

DISCLN-2.CHP (1-91) 


\title{
A MODEL FOR DETERMINING WHEN AN
}

\author{
ANALYSIS CONTAINS SUFFICIENT DETAIL
}

\section{TO PROVIDE ADEQUATE}

\section{NEPA COVERAGE FOR A PROPOSED ACTION}

\author{
C. H. Eccleston
}

Abstract

Neither the National Environmental Policy Act (NEPA) nor its subsequent regulations provide substantive guidance for determining the level of detail, discussion, and analysis that is sufficient to adequately cover a proposed action. Yet, decisionmakers are routinely confronted with the problem of making such determinations. Experience has shown that no two decisionmakers are likely to completely agree on the amount of discussion that is sufficient to adequately cover a proposed action. One decisionmaker may determine that a certain level of analysis is adequate, while another may conclude the exact opposite. Achieving a consensus within the agency and among the public can be problematic.

Lacking definitive guidance, decisionmakers and critics alike may point to a universe of potential factors as the basis for defending their claim that an action is or is not adequately covered. Experience indicates that assertions are often based on ambiguous opinions that can be neither proved nor disproved. Lack of definitive guidance slows the decisionmaking process and can result in project delays. Furthermore, it can also lead to inconsistencies in decisionmaking, inappropriate levels of NEPA documentation, and increased risk of a project being challenged for inadequate coverage. A more systematic and less subjective approach for making such determinations is obviously needed.

A paradigm for reducing the degree of subjectivity inherent in such decisions is presented in the following paper. The model is specifically designed to expedite the decisionmaking process by providing a systematic approach for making these determination. In many cases, agencies may find that using this model can reduce the analysis and size of NEPA documents. 
On New Years day, 1970, the National Environmental Policy Act (NEPA) was signed into law, declaring that environmental quality was a national priority, and establishing a Council on Environmental Quality (CEQ) to oversee the NEPA Act. ${ }^{1}$ Early on the courts played a major role in implementing NEPA. One case laid to rest any doubts concerning the scope of judiciary review, Strycker's Bay Neighborhood Council v. Karlan. ${ }^{2}$ The decisions in Strycker's Bay reinforce the clear intent of NEPA that environmental quality is an integral part of every agency's mission and must be considered along with other national policy objectives. $^{3}$

In 1978 the CEQ issued regulations (Regulations) for implementing NEPA and preparing environmental impact statements (EIS). ${ }^{4}$ To this day, however, questions concerning the amount and level of detail that is sufficient to provide an adequate analysis remain. A universal solution to this problem has been elusive because of the diversity of federal actions and the different aspects of the environment they affect.

The courts have not been reluctant to become involved in determining the adequacy of environmental processes undertaken by federal agencies. To avoid the risk of litigation, federal agencies have tended to create large and cumbersome environmental 
analyses that included every conceivable impact and issue, rather than sharply defined analyses of probable impacts and reasonable options.

\section{THE PROBLEM OF DETERMINING WHAT CONSTITUTES ADEQUATE COVERAGE UNDER NEPA}

Since the inception of NEPA and its subsequent regulations, no definitive direction has been established for determining the amount of detail, discussion, and analysis that is sufficient to adequately cover a proposed action. Yet, agency decisionmakers are routinely called upon to do just that. Lacking a systematic procedure, these determinations tend to be very subjective.

The courts have provided some generic guidance regarding this issue. To date, this guidance has generally been vague and has varied widely. Table 1 summarizes characteristics of EISs that have been found to be inadequate and those that have been judged to have sufficient information to enable decisionmakers to consider the environmental effects and make reasonable decisions. 


\begin{tabular}{|c|c|}
\hline Inadequate Characteristics ${ }^{5}$ & Adequate Characteristics \\
\hline $\begin{array}{l}\text { - Ignore important topics } \\
\text { - Exude arrogance } \\
\text { - Demonstrate a reluctant and } \\
\text { begrudging compliance } \\
\text { Contain discussion or } \\
\text { conclusions that are: } \\
\text { Sweeping } \\
\text { Vague } \\
\text { Unsupported by fact } \\
\text { Scientifically undefensible } \\
\text { Wholly unquantified } \\
\text { Incomprehensible } \\
\text { Internally contradictory } \\
\text { Basically flawed } \\
\text { Misleading or incomplete } \\
\text { Excessively cryptic } \\
\text { Argumentative } \\
\text { Genuinely preposterous } \\
\text { Dependent on stale data or biased } \\
\text { procedures }\end{array}$ & $\begin{array}{l}\text { - Presents more than a mere listing of } \\
\text { alternatives } \\
\text { - Discusses: } \\
\text { Connected actions' } \\
\text { Reasonable direct and indirect impacts } \\
\text { significant aspects of the probable } \\
\text { consequences thoroughly and objectively }{ }^{10} \\
\text { Cumulative impacts } \\
\text { Synergistic effects }{ }^{12} \\
\text { - Presents information that is sufficient to } \\
\text { enable the decisionmaker to consider the } \\
\text { environmental effects and make a reasonable } \\
\text { decision }{ }^{13}\end{array}$ \\
\hline
\end{tabular}

\section{Except for major deviations from Section 102(2)(C) of NEPA, the} grounds for determining adequacy or inadequacy of NEPA documentation defy summary. While the courts have suggested basic 
characteristics of inadequacy, they sti11 have not, by-and-large, provided detailed guidance that allows one to determine if the information contained in an analysis is sufficient to provide adequate coverage. In determining the adequacy of NEPA coverage, analysts and decisionmakers alike, must exercise a considerable degree of reason and judgment. Without this reason and judgment, an argument can be made that the NEPA analysis and documentation process could continue ad infinitum.

In some cases, an aspect of a proposed action may be considered to be covered by merely mentioning that the specific action will take place. In others, an extensive analysis may be considered necessary. If the analysis is considered to be insufficient to provide adequate coverage, additional NEPA documentation may need to be prepared.

Expectations regarding the adequacy of coverage may reflect an individual's responsibility, personal bias, technical training, and experience. Experience has shown, for example, that no two decisionmakers will likely agree completely on the amount of discussion needed to provide coverage sufficient to allow the agency to implement a proposed action. The outcome of such reviews is problematic; if two decisionmakers agree that a particular discussion does not provide adequate coverage, they may 
still disagree on the degree of analysis and discussion needed. Proponents of a project may believe that a NEPA analysis provides sufficient coverage for a proposed project, while critics may argue that the analysis needs to be taken to increasingly detailed levels.

Lacking definitive guidance, decisionmakers and critics may point to a universe of potential factors that can be used to defend a position that an action is or is not adequately covered. Assertions are often based on ambiguous opinions that can neither be proved nor disproved. While common sense is an integral part of decisionmaking, definitive guidance would greatly reduce the degree ambiguity and subjectivity that currently exists. The following example more clearly illustrates the specific nature of the problem and the need to develop consistent guidance.

\section{Determining if a Hazardous Waste Incinerator is Adequately Covered}

Suppose that an agency prepares an EIS for an incineration facility that would treat hazardous waste. The proposed action involves shipping waste to the incineration facility where it would be stored for later incineration. Before incineration, the waste would be treated in a pretreatment facility to separate fractions that are not suitable for incineration. 
The EIS provides a detailed analysis and description of both the pretreatment facility and incinerator. However, it simply states that the waste would be shipped to the site for incineration. Furthermore, it only briefly mentions that a large storage facility would be constructed for storing the waste before incineration. The EIS does not include an analysis of impacts associated with an accident involving transporting of the waste to the site; nor does it include an analysis of the impacts that could result from a fire or other accident that might occur within the storage facility.

Is a terse discussion of transportation and construction of a 1 arge waste storage facility sufficient to cover the project? If not, what degree of analysis is necessary to provide sufficient coverage? What basis does a decisionmaker have for making such determinations?

If a determination is made that additional coverage is needed, the agency might consider preparing and tiering an Environmental Assessment (EA) to cover transportation and construction of the waste storage facility. Even if subsequent EAs are prepared and tiered from the EIS, a case could still be made that even more detailed EAs may later be necessary when the project and its impacts are more thoroughly understood. In theory, the tiering 
process could continue ad infinitum. Again, one is left with the task of determining when the analysis is considered sufficient to provide adequate coverage.

Before continuing further, consider the specific nature of this problem, which can best be defined by posing the following question:

How much discussion and analysis must be presented in a NEPA document to provide sufficient coverage for an agency to pursue a proposed action?

\section{Lack of Definitive Guidance Increases Risk and Leads To} Inefficiencies

An inordinate amount of time and resources is often consumed reviewing NEPA documentation to determine if the amount of discussion and analysis provides sufficient coverage. Ultimately, lack of definitive guidance can also result in project delays, inconsistencies in the treatment of NEPA documents, and risk that a project may be challenged for inadequate coverage. To reduce such risk, agencies often prepare NEPA documents containing a level of detail much greater than is reasonably necessary to 
provide adequate coverage. Such overkill can significantly increase the cost of the NEPA analysis and may result in project delays.

Moreover, the agency's internal and public comment/review process typically involves a variety of participants (i.e., reviewers, commenters, decisionmakers), providing a wide array of comments and opinions, many of which may conflict with one another. Because no definitive guidelines exist concerning the amount of detail that is sufficient, documents often suffer from "detail inflation" as analysts attempt to respond to a diverse range of comments. That is, the level of detail often expands rapidly as an agency attempts to respond to technicalty demanding review comments that often add little or no additional value to the actual decisionmaking process.

Clearly, a consistent and systematic approach is needed to assist decisionmakers in determining when an action is sufficiently covered. The following section presents a basis for such an approach . 
TOWARDS A MORE OBJECTIVE AND SYSTEMATIC MODEL FOR DETERMINING ADEQUACY

In developing a defensible model, one might best begin by asking a simple question: "What is the fundamental intent and purpose of NEPA?". The answer to this question provides a starting point for developing a model, because no model will work unless it fulfills the underling purpose and intent of NEPA.

According to the Regulations, the fundamental intent and purpose of NEPA is to foster excellent decisionmaking by taking environmental factors into consideration. Specifically, NEPA "... is intended to help public officials make decisions that are based on an understanding of environmental consequences...". The Regulations go on to state that agencies are required to prepare NEPA documents that "concentrate on issues that are truly significant to the action in question, rather than amassing needless detail." Furthermore, this environmental information is to be made available to "public officials and citizens before decisions are made and before actions are taken."14 These requirements provide a starting point for the proposition that follows. 


\section{A Starting Point}

Experience indicates that a point of 'diminishing returns' will aTways be reached beyond which additional information will not contribute substantially to the decisionmaking process. Based on this proposition, the amount of detail and analysis is generally adequate if a more detailed discussion of the issue or topic would not provide information that would substantial1y improve the agency's ability to make decisions. After all, what purpose is served by providing more detailed if the information would not improve a decisionmaker's ability to make informed decisions? Pursuing an analysis beyond this point is an exercise in futility and is inconsistent with direction provided in the Regulations. For instance, it violates a key mandate to reduce excessive paperwork by: emphasizing material that is "useful to decisionmakers and the public and reducing emphasis on background material", deemphasizing "insignificant issues", and discussing "only briefly issues other than significant ones."15

Alternatively, including additional discussion and analysis is warranted if it can be reasonably concluded that the information would allow decisionmakers to make more informed decisions. This simple premise provides the cornerstone for the model which wi11 be described shortly. 


\section{THE BASIS FOR DEVELOPING A MODEL FOR DETERMINING ADEQUATE COVERAGE}

The model described below, does not promote any degree of decisionmaking beyond the level that is already routinely exercised. Instead, the model attempts to provide decisionmakers with a rigorous, systematic, and defensible approach for making such determinations.

As shown in Figure 1, four criteria (or tests) have been identified that provide the technical basis for the model that will be described in Figure 2.

The criteria are based on the premise, that no useful purpose is served in providing additional detail if the information would not in someway improve the decisionmaking process. Each criterion also reflects specific provisions that are mandated in the Regulations. The specific provisions are cited for each criterion shown in Figure 1. 
Figure 1. Criteria for Determining if the Discussion and Analysis is Sufficient to Provide Adequate Coverage

Would a more detailed analysis:

- Contribute substantially, to the understanding of environmental impacts? A more detailed analysis is justified if it provides information that could substantially improve the agency's understanding of the impacts. (40 CFR $1500.1(\mathrm{c}), 1502.1$ )

- Substantially change the agency's decision? Specifically, would the discussion allow the agency/public "to concentrate on the issues that are truly significant to the action in question" or would it simply amount to an exercise in "amassing needless detail"? A more detailed analysis is justified if, based on environmental factors, it could substantialiy affect the agency's decision. (40 CFR 1500.1(c), $1500.4(c),(f)$, and (1))

- Contribute substantially, to the public's understanding or acceptance/rejection of the proposed 
action/a7ternatives? NEPA is a public process; a more detailed analysis is warranted if it could substantially affect the public's assessment (positively or negatively) of the action or could substantially affect public's ability to provide comments or input into the decisionmaking process. (40 CFR 1500.2(b) and (d), 1500.4(f), 1501.4(b), 1502.1, $1500.1(b))$

- Result in new measures that could substantially reduce the impacts associated with the project? A more detailed analysis is justified if it may result in identifying mitigation measures that could substantial1y reduce adverse impacts (40 CFR $1500.2(f), 1502.1,1502.14(f), 1500.1(c))$ 


\section{A MODEL FOR DETERMINING THE SUFFICIENCY OF NEPA COVERAGE}

The model shown in Figure 2 is based on the criteria established in Figure 1. The model must be implemented on a case-by-case basis. Professional judgement must be exercise in cases where the answer to any test is not clearly obvious.

This model can be employed at various steps throughout the life-cycle of the NEPA process. While preparation of a document is underway, for example, the model may be used by analysts to determine if existing discussion of a specific issue or topic is sufficient. If not the model may assist analysts in determining how much additional analysis is necessary. Once the document has been prepared, the model may be used by reviewers in determining if particular topics or issues are adequately covered. During the comment incorporation process, the model may assist analysts in determining if a comment is relevant, as well as the amount of discussion that may be warranted. Moreover, the model may assist decisionmakers in determining if the amount of detail, discussion, and analysis is sufficient to support a final decision to pursue a proposed action. Finally, if the agency is challenged, the model might provide a basis for determining if the agency's analysis is sufficient to provide adequate coverage for pursuing a proposed action. 


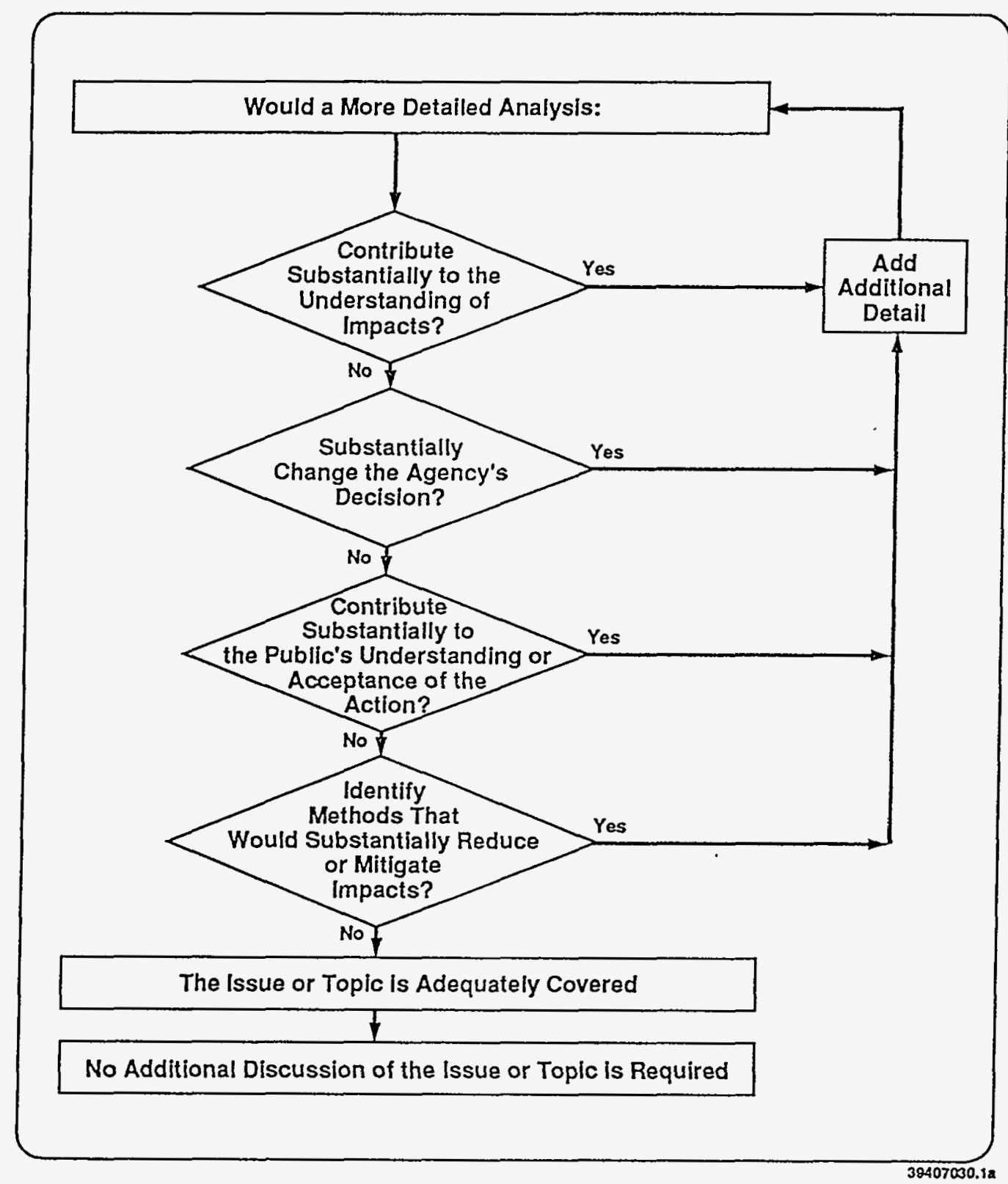

Figure 2. Model for determining if the discussion of a topic or issue is sufficient to provide adequate NEPA coverage. 
The mode1 can be applied to an array of different NEPA documentation requirements. Specifically, the model can be used in determining if there is sufficient discussion of the proposed action and alternatives, analysis of environmental impacts, discussion of affected environment, and the appropriateness of introductory and background material.

As indicated in Figure 2, application of the model begins with the review of a particular topic or issue that either is or will be discussed. The review is conducted by examining each of the four tests with respect to the following question: "Would a more detailed analysis...".

A "no" answer to all four tests supports a decision that the issue or analysis has been sufficiently covered. There appears to be little justification for preparing a more detailed analysis unless the answer to one or more of these questions is "yes".

A "yes" answer to any test would support a decision that a more detailed discussion or analysis is warranted. Once the additional analysis has been included, this process is repeated i.e., the model is again used to determine if the analysis is now sufficient. This process is continued until a "yes" response is no longer invoked. 
Advantages and Limitations of the Model

The model is applicable to a broad array of topics and agency actions that must be addressed under NEPA. As with any model, however, exceptions may arise that cannot be appropriately addressed. Other factors may also need to be considered before making a final decision regarding the adequacy of an analysis.

Admittedly, the model does not completely eliminate subjectivity. After all, decisionmaking by its very nature is subjective. No two decisionmakers, for example, are likely to completely agree on whether a more detailed analysis would contribute substantially to an understanding of the environmental impacts. While this model does not completely eliminate such subjectivity, it significantly reduces it because the universe of potential considerations that can be used to justify a particular position, is essentially reduced to four narrowly defined tests. Under this model, decisionmakers and critics alike, would be expected to provide specific and rational arguments, justifying, why in their view, the analysis does or does not meet one or more of the four tests. 


\section{Establishing Criteria for Evaluating the Four Tests}

Before beginning the analysis, the agency may decide to establish specific criteria for evaluating the four tests presented in the mode1. An agency might consider using the NEPA process to identify and evaluate such criteria. For instance, specific criteria may be developed as part of the scope of an EIS. This criteria could then be used in evaluating subsequent documents. Once developed, the criteria could then be used for determining adequacy of coverage in subsequent and lower-tier NEPA documents. The Regulations identify 10 factors that should be considered in determining the significance of an impact. ${ }^{16}$ These significance factors might provide a basis for identifying specific criteria that can be used to evaluate each test. For instance, a criterion might be based on one of the significance factors that involve actions that are "highly controversial."17 This criterion could prescribe specific conditions that are indicators of controversial. With respect to the issue of controversy, the analysis might be considered sufficient, if in a decisionmaker's best professional judgment, a more detailed analysis would not identify new impacts that are likely to be "highly controversial."

Similarly, a second criterion might be based on another significance factor involving actions that could potentially 
violate Federal, State, or local environmental laws or requirements. ${ }^{18}$ In this case, an action could be considered covered if a decisionmaker can reasonably concluded that a more detailed analysis would not identify additional impacts that would threaten to violate an environmental law or requirement. Using this approach, criteria for determining adequacy of coverage might be developed using all 10 significance factors cited in the Regutations.

\section{WHY THE MODEL IS DEFENSIBLE}

No discussion of this approach would be complete without addressing the question of defensibility. That is: Can an agency legitimately adopt such a model to determine if an analysis provides sufficient coverage to pursue an action? As we will see, agencies not only have the prerogative to adopt such methodologies, but are in fact, actually encouraged by the Regulations to do so. 
Agencies have been Given Wide Degree of Latitude to Adopt Approaches for Implementing the NEPA Process

A review of the Regulations reveals that agencies have been given not only the right but the responsibility to develop specific procedures, techniques, and methodologies for implementing the NEPA process. The Regulations were specifically designed to provide agencies with flexibility to tailor the NEPA process to their own needs. Consistent with this philosophy, the Regulations place only minimal restrictions on how agencies must implement the NEPA process. To underscore this philosophy, consider the following direction that is provided in the Regulations:

- Agencies shall "utilize a systematic" approach. ${ }^{19}$

- "It is the intent of these regulations to allow each agency flexibility in adapting its implementing procedures..." 20

- Agencies shall "Identify methods and procedures ... to insure that presently unquantified environmental amenities and values may be given appropriate consideration". ${ }^{21}$ 
Daniel Mandelkar lends further support to the validity and defensibility of the proposed model:

\footnotetext{
"Because a consensus is usual7y lacking on the state of the art in environmental methodology, the courts have usual7y accepted the methodology used by an agency in analyzing environmental impacts. They put the burden of proof on plaintiffs to prove that the methodology was unacceptable...These decisions reflect the usual judicial willingness to uphold the agency when the evidence shows that there is only a disagreement among experts. ${ }^{22}$
}

Determinations of Coverage are Routinely Made Without a Formal and Systematic Basis

Decisionmakers are routinely involved in making determinations regarding the adequacy of coverage. Lacking a formal and systematic procedure, these determinations often tend to be made on an ad hoc basis.

The proposed model does not promote any degree of decisionmaking beyond the level that is already exercised by agencies on a routine basis. Instead, it attempts to substitute a rigorous and 
systematic approach for the haphazard way in which determination are currentiy made. If agencies have authority to make determinations on an ad hoc basis, certainty a systematic approach is equally defensible. Accepting this model amounts to nothing more that substituting a more formal and systematic procedure for the informal and inconsistent process that is typically used.

\section{SUMMARY}

Agencies are routinely involved in reviewing NEPA documents to determine if the amount of detail, discussion, and analysis is sufficient to provide coverage for an action. Definitive guidance does not exist for making such determinations. As a result, decisionmakers and critics alike, may point to a universe of factors as the basis for defending their position. Consequently, an inordinate amount of time and resources may be consumed reviewing such issues, slowing the decisionmaking process, and increasing the risk of project delays. It may also lead to inconsistencies in determinations, inappropriate levels of NEPA documentation, and increased risk that a project may be challenged. 
The degree of subjectivity inherent in the decisionmaking process is significantly reduced using the proposed model, because the universe of potential considerations and justifications that may be used as the basis for making such determinations are essentially reduced to four narrowly defined tests. Accordingly, this model can help streamline the NEPA process by reducing the time and resources required to make determinations, while increasing the defensibility of the agency's decision.

The proposed model does not promote any level of decisionmaking beyond that already exercised on a regularly basis. Instead, it merely provides decisionmakers with a rigorous, systematic, and defensible approach for making such determinations. Certainly, a rigorous and systematic procedure, firmly based on direction provided in the Regulations, is preferable to a process that has typically been carried out haphazardly.

\section{ACKNOWLEDGMENTS}

I wish to thank Ms. B. D. Williamson (Westinghouse Hanford Company [WHC], Legal Department) who reviewed this paper and contributed to the legal research. Special thanks is also extended to $\mathrm{Mr}$. P. F. X. Dunigan (NEPA Compliance Officer, U.S. Department of Energy, 
Richland Field Office), Mr. R. H. Engelmann (Manager of NEPA Services, WHC), and Mr. Frederic March, (Los Alamos Technical Associates), who reviewed this paper and contributed valuable suggestions .

\section{REFERENCES}

1. 42 United States Code (USC) 4321-4347, "The Nationa1 Environmental Policy Act of 1969, "United States Code, as amended.

2. Strycker's Bay Neighborhood Council v. Karlan, 444 U. S. 223 (1980)

3. Robertson v. Methow Valley Citizens Council, $109 \mathrm{~S}$. Ct. 1835,1846 (1989).

4. 40 Code of Federal Regulations (CFR) 1500-1508, "Regulations for Implementing the Procedural Provisions of the National Environmental Policy Act," Code of Federal Regulations, November 29, 1978. 
5. Rogers, William H., Jr., Handbook on Environmental Law, West Publishing Co., St. Paul, Minn., 1977, pages 731 to 733.

6. Robertson v. Methow Valley Citizen Council, 409 U.S. 332, 335 (1989).

7. Blue Ocean Preservation Society v. Watkins, 754 F. Supp. 1450, 1459 (1991); See a1so, Puna Speaks V. Edwards, 554 F. Supp. 117 (1992).

8. Sierra Club v. Marsh, 976 F. Supp. 763, 770 (1992).

9. Idaho Conservation Leaque v. MUMMA, Lexis 9031,32 (U.S. App., 1992).

10. Holy Cross Wilderness Fund V. Madigan, 960 F.2d 1515, 1522 (1992).

11. City of Tenakee Springs v. Clough, 915 F. 2d 1308, 1312 (1990).

12. Sierra Club V. Penfold, 664 F. Supp. 1299, 1314 (1987). 
13. Half Moon Bay Fisherman's Marketing Association v. Carlucci, 857 F. Supp. 505, 512 (U.S. App., 9th Circ., 1988).

14. 40 CFR 1500.1

15. 40 CFR 1500.4 Reducing paperwork

16. 40 CFR $\S 1508.27$ (b), Significantly.

17. 40 CFR 1508.27 (b) (4)

18. 40 CFR 1508.27 (b) (10)

19. 40 CFR 1507.2 (a)

20. 40 CFR 1507.1

21. 40 CFR 1507.2 (b)

22. Mandelkar, Daniel R., 1993, NEPA Law and Litigation, Chapter 10, Clark, Boardman, and Callaghan. 